\title{
DEL PATRIMONIO AL CARNAVAL DE RÍO Y LAS ESTRUCTURAS URBANAS: LA TRAYECTORIA INTELECTUAL DE NELSON DA NOBREGA FERNANDES
}

\author{
HORACIO CAPEL
}

El día 26 de junio pasado murió el geógrafo brasileño Nelson da Nobrega Fernandes, profesor de la Universidade Federal Fluminense, después de una rápida e inesperada enfermedad. Era un conocido especialista en la cultura popular, en el patrimonio histórico y en la geografía urbana, y estaba desarrollando en la actualidad nuevas líneas de investigación muy prometedoras.

Era una persona muy querida, generosa, amable y de una gran humanidad. Su pérdida ha afectado profundamente a toda la geografia brasileña e ibero-americana. Y de manera especial al grupo de Geocrítica, al que ha estado vinculado desde hace dos decenios. Recientemente realizó una larga estancia postodoctoral senior en la Universidad de Barcelona, junto con su mujer, la profesora María Lucia Pires Menezes, por lo que estuvieron vinculados durante más de un año al Departamento de Geografía Humana y al grupo Geocrítica, hasta el mes de abril de este año. Su presencia constante y la cálida convivencia con sus colegas ha dejado una profunda huella.

Su estancia en Barcelona estuvo marcada por una rápida integración en la ciudad, por su colaboración académica y, especialmente, por su interés sincero en los procesos de cambio social y urbanístico que se están produciendo, de los cuales siempre estuvo informado y al día. Se integró bien en el ambiente ciudadano y colaboró con la revista La Veu del Carrer, de la Federación de Asociaciones de Vecinos de Barcelona, donde publicó el artículo "Brasil se levanta por el derecho a la ciudadania".

Nelson Fernandes fue durante muchos años técnico del Instituto de Patrimonio Histórico e Artístico Nacional (IPHAN). Como tal, participó en investigaciones y estudios para la defensa de los bienes culturales de las ciudades brasileñas, y para la preservación del centro histórico de Rio. 
En 2001 presentó su Tesis Doctoral en la Universidad Federal de Rio de Janeiro, dirigida por la profesora Iná Elias de Castro, sobre el tema Festa, cultura e identidade nacional. As escolas de samba do Rio de Janeiro (1928-1949). En ella se planteó lo que un autor había calificado como el "mistério do samba"; es decir la rápida difusión de este baile, que pasó de ser un género despreciado en las tres primeras décadas del siglo XX, por tratarse de una música producida y bailada por negros y mestizos de las favelas, a convertirse en los años 1930 en un símbolo de la identidad nacional brasileña.

La samba se incorporó al Carnaval como un ritmo que permitía desfilar bailando, y aportaba gran novedad a unos desfiles en que dominaban bandas y orquestas, con fuerte presencia de los instrumentos de viento. Para adecuarse al ritmo del desfile se intensificó el uso de los instrumentos de percusión, e incluso se inventaron nuevos instrumentos como la "cuíca" y el "surdo". Todo lo cual dió como resultado una nueva cadencia del ritmo de la samba.

La Tesis de Nelson Fernandes abordó el importante tema de la cultura popular. Dos posiciones extremas pueden detectarse acerca de la creación de la samba: una que defiende que es una creación popular reconocida por los grupos cultos; y otra que considera que es una elaboración culta vulgarizada y difundida de arriba abajo. Ésta implicaría que el desarrollo de la samba era una estratagema de la clase dominante para controlar y 'domesticar' a la clase obrera y afirmar el mito de la democracia racial en Brasil. Frente a ella, Nelson Fernandes defendió que las clases populares pueden "reelaborar y proyectar nuevos sentidos para los valores y las ideologías que les son impuestos", y que consiguieron "ganar legitimidad política y cultural para su práctica festiva". Con la incorporación de la samba, los negros y los mestizos - que en esa época a veces eran considerados todavía como razas inferiores, con las que no podía construirse una nación moderna y civilizada-irrumpieron en la fiesta y se hicieron dueños de ella.

En la Tesis se estudia la creación de las escuelas de samba en los morros de Serrinha, Osvaldo Cruz y Mangueira, la evolución de los primeros grupos, el apoyo que recibieron de parte de algunos periódicos, principalmente del diario Mundo Esportivo, que organizó el primer concurso de escuelas de samba del carnaval de 1932, en el que participaron ya 19 grupos. La samba también proporcionó cohesión a los grupos populares que organizaron las escuelas; y les permitió acometer luchas populares; por ejemplo la 
que iniciaron en 1934 los habitantes del morro de Salgueiro hasta conseguir paralizar el intento de expulsión por parte de un promotor.

Además de esa aportación fundamental, Nelson Fernandes ha sido un especialista importante en morfología urbana, en historia urbana, en desarrollo, planeamiento y gestión de la ciudad capitalista, con el ejemplo de Rio. Sus investigaciones en este sentido han tenido gran repercusión, especialmente el libro sobre $O$ rapto ideológico da categoria subúrbio: Rio de Janeiro, (1858-1945.), y el editado con Marcio Piñón de Oliveira 150 años de subúrbio carioca. También ha trabajado sobre ideologias y representaciones del espacio, identidades sociales, renta de la tierra en la ciudad, y sobre los agentes urbanos y los procesos de transformación espacial de Rio de Janeiro.

Se esforzó también en encontrar lo elementos comunes de las ciudades capitalistas, desde sus primeros desarrollos en la edad moderna hasta el actual sistema mundial global. En este sentido, intentó elaborar un esquema general de los patrones morfológicos de larga duración, y las diferencias estructurales entre las ciudades europeas y americanas, insistiendo en la inclusión de las ciudades brasileñas en el sistema capitalista desde la edad moderna.

Su interés investigador se extendió a la arqueología industrial, el equipamiento comercial urbano, los procesos de electrificación (Eletrificação do sistema suburbano da Estrada de Ferro Central do Brasil e a política urbana no Rio de Janeiro. En La electricidad en las redes ferroviarias y la vida urbana: Europa y America (siglos XIX-XX). Madrid: Fundación de los Ferrocarriles Españoles, 2012)

También estudió las estructuras de poder en las capitales administrativas, con el ejemplo de las de Acre, en un trabajo con su mujer Maria Lucia Pires Menezes, y la crisis del federalismo en la época de la globalización.

Actualmente estaba investigando acerca la incidencia de las estructuras militares en el territorio, un proyecto que estaba ya bien formulado desde 2006 (Os militares e o espaço do Rio de Janeiro, como un programa de investigación en geografia urbana y en geopolítica. En relación con él se ocupó del papel de las fuerzas armadas en el desarrollo y configuración de las ciudades, y en especial de las áreas suburbanas, y sobre la influencia de las políticas militares en el origen de la vivienda social en Brasil, sobre lo que publicó 
$<$ http://www.geocritiq.com/2013/11/urbanizacao-militar-e-as-origens-dahabitacao-social-no-brasil/>.

El camino intelectual de este geógrafo le llevó del estudio del patrimonio, al de la introducción del baile de la samba en el Carnaval de Rio de Janeiro, y al problema de la cultura popular; y de aquí al estudio de las estructuras urbanas en esta ciudad y en otras de Brasil, así como, finalmente a cuestiones geopolíticas y militares. Temas todos tratados con una gran imaginación, como es habitual en la geografía brasileña, una de las más importantes escuelas de geografía del mundo. Nelson nos ha dejado, pero su obra y su recuerdo permanecerán siempre entre nosotros. 